\title{
ANALISIS IMPLEMENTASI SISTEM INFORMASI AKUNTANSI DENGAN MENGGUNAKAN SOFTWARE ACOSYS PADA PT LADFANID KONSULTINDO BATAM
}

\author{
Argo Putra Prima ${ }^{1}$, Jefri Akbar ${ }^{2}$ \\ Universitas Putera Batam \\ email: argo.putra@puterabatam.ac.id
}

\begin{abstract}
The purpose of this study is to examine the use of an accounting system using Microsoft Excel, the reliability of the accounting system used previously as well as the factors that influence the successful implementation of the Acosys software-based accounting information system at PT Ladfanid Konsultindo Batam. In implementation, in Microsoft Excel presenting financial statements, especially for trading and manufacturing companies in the calculation of cost of goods sold, there must be a classification beforehand because Microsoft Excel does not have a special menu in the presentation of purchases and sales so that there are several classifications in different sheets. The accounting system used today is Acosys, which is an accounting system that is more adequate and reliable than using Microsoft Excel. Acosys can be categorized as a complex system in preparing financial statements because it has features that can be used according to company needs. every transaction that has been inputted automatically all kinds of reports relating to finance can be accessed quickly as needed. What is rarely owned by other software but owned by Acosys is that Acosys software can be used forever without additional costs for updating.
\end{abstract}

Keywords: Acosys; Microsoft Excel; Accounting System.

\section{PENDAHULUAN}

Kemajuan teknologi informasi yang pesat serta ini seharusnya menjadi potensi dalam pemanfaatannya secara luas,membuka peluang bagi pengaksesan, pengelolaan, dan pendayagunaan informasi dalam volume yang besar secara cepat dan akurat dalam hal ini sistem informasi harus bisa menjadi manfaat besar bagi penggunanya. Untuk memajukan usaha bisnis diperlukan dukungan manajemen yang tepat dan dalam mengelolanya diperlukan informasi yang teliti, tepat, dan cepat. Demikianlah kecenderungan bisnis di abad informasi dewasa ini, berkembang pesat dan penuh liku-liku persaingan serta maju mundurnya sangat tergantung kepada informasi yang dikelolanya, oleh karena itu untuk memelihara serta meningkatkan kegiatan secara optimal sistem informasi yang sudah ada dalam sistem perusahaan perlu dievaluasi ulang agar tercipta suatu sistem informasi yang lebih baik begitu juga dengan PT Ladfanid Konsultindo Batam. Dalam banyak praktek, ditemukan bahwa implementasi sistem informasi akuntansi di lapangan sering menemui berbagai macam kendala. Mulai dari sistem informasi tersebut tidak sesuai dengan kebutuhan, bahkan bisa jadi penggunaan sistem informasi justru menurunkan kinerja perusahaan dalam melakukan pelayanan terhadap konsumen. Setelah sistem Acosys, penulis ingin mengetahui apa yang terjadi pada saat sistem informasi tersebut diimplementasikan, apakah implementasi sistem informasi penjualan tersebut banyak menemui kendala atau tidak, dapat memberikan dampak yang positif atau malah justru memberikan dampak negatif setelah menggunakan software Acosys

\section{TINJAUAN PUSTAKA}

Sistem Informasi Akuntansi

Istilah Sistem Informasi Akuntansi (SIA) baru mulai dipopulerkan sekitar tahun 1980an. Sistem informasi akuntansi adalah sekumpulan sumber dana dan daya (resources), seperti 
orang dan peralatan yang dirancang untuk mentransformasi data keuangan dan data data lainnya menjadi informasi. Informasi ini dikomunikasikan kepada para pengambil keputusan yang sangat beragam (Bodnar, 2010). Menurut (Ardana, 2016) Akuntansi (SA) organisasi formulir, catatan, dan laporan yang dikoordinasikan sedemikian rupa untuk menyediakan informasi keuangan yang dibutuhkan oleh manajemen guna memudahkan pengelolaan perusahaan. Menurut (Widjajanto, 2010) dalam bukunya "Sistem Informasi Akuntansi"(2008:30), menyatakan bahwa : "Sistem informasi akuntansi adalah susunan formulir, catatan, peralatan termasuk komputer dan perlengkapannya serta alat komunikasi, tenaga pelaksanaannya dan laporan yang terkoordinasi secara erat yang didesain untuk mentransformasikan data keuangan menjadi informasi yang dibutuhkan manajemen".

\section{Software Acosys}

Acosys adalah salah satu software akuntansi yang diproduksi oleh perusahaan asal Indonesia bernama PT. Acosys Global Data atau yang lebih dikenal dengan nama komersil Aztechsoft Int. Aplikasi ini berguna untuk memudahkan aktivitas dan pencatatan transaksi pembelian, penjualan, persediaan, aset tetap, dan lain-lain. Output yang dihasilkan adalah laporan-laporan pembelian, penjualan, persediaan, aset tetap, dan lain-lain serta berbagai laporan keuangan perusahaan seperti neraca, laba rugi, perubahan ekuitas, laporan arus kas, dan analisa rasio. Acosys dibuat dengan menggunakan IDE open source bernama MSEide+MSEgui yang dikembangkan oleh programmer dari Switzerland bernama Martin Schreiber. Sebelum menjadi Acosys, nama aplikasi ini adalah AGRS. Pada Tahun 2001 AGRS dikelola resmi oleh perusahaan berbadan hukum yang memakai merek dagang Aztechsoft Int. Tahun 2002 AGRS berubah nama menjadi Acosys versi 1. Sampai dengan Acosys versi 3 Acosys hanya dapat dijalankan dari sistem operasi Windows saja. Tetapi sejak versi 4, Acosys dapat dijalankan di sistem operasi Windows dan Linux dengan tampilan yang sama. Acosys adalah software akuntansi Indonesia yang memiliki fitur sederhana dan dapat digunakan oleh perusahaan dengan bisnis yang lebih spesifik.

\section{METODE}

\section{Variabel Penelitian}

Penelitian ini bersifat kualitatif, dimana menggunakan variabel implementasi sistem informasi akuntansi dengan menggunakan software Acosys.

\section{Sistem Informasi Akuntansi}

Sistem informasi akuntansi adalah susunan formulir, catatan, peralatan termasuk komputer dan perlengkapannya serta alat komunikasi, tenaga pelaksanaannya dan laporan yang terkoordinasi secara erat yang didesain untuk mentransformasikan data keuangan menjadi informasi yang dibutuhkan manajemen.

\section{Software Acosys}

Acosys adalah salah satu software akuntansi yang diproduksi oleh perusahaan asal Indonesia bernama PT. Acosys Global Data atau yang lebih dikenal dengan nama komersil Aztechsoft Int. Aplikasi ini berguna untuk memudahkan aktivitas dan pencatatan transaksi pembelian, penjualan, persediaan, aset tetap, dan lain-lain. Output yang dihasilkan adalah laporan-laporan pembelian, penjualan, persediaan, aset tetap, dan lain-lain serta berbagai laporan keuangan perusahaan seperti neraca, laba rugi, perubahan ekuitas, laporan arus kas, dan analisa rasio.

\section{Teknik Pengumpulan Data \\ Metode Observasi}

Metode observasi atau pengamatan adalah cara pengumpulan data dengan cara melakukan pencatatan secara cermat. Kalau pengamatan dilakukan dengan sambil lalu dan tidak memenuhi prosedur dan aturan yang jelas, tidak bisa di sebut observasi. Dalam metode ini penulis melakukan pengamatan langsung pada objek yang diteliti mengenai prosedur sistem 
informasi akuntansi dengan menggunakan software akuntansi Acosys. Peneliti melakukan transaksi langsung terkait dengan penyajian laporan keuangan pada PT Ladfanid Konsultindo Batam. Untuk mengtahui jalannya sistem akuntansi dengan menggunakan Acosys. Dengan mencoba fitur-fitur yang digunakan sesuai dengan arahan dan modul dari karyawan.

\title{
Metode Wawancara
}

Wawancara merupakan metode pengumpulan data dengan cara bertanya langsung (berkomunikasi langsung) dengan responden. Data yang digunakan data primer yaitu data yang diperoleh langsung dari pihak perusahaan yaitu dengan wawancara dan observasi pada bagian yang terkait dalam perusahaan. Penulis melakukan wawancara kepada karyawan PT Ladfanid Konsultindo Batam. Dalam metode ini penulis melakukan wawancara secara langsung terhadap pihak yang terkait terutama pada karyawan yang bekerja tentang sistem informasi akuntansi dalam menyajikan laporan keuangan klien PT Ladfanid Konsultindo Batam dengan menggunakan Acosys.

Metode Kepustakaan

Menurut (Mestika, 2008) "Metode Kepustakaan merupakan serangkaian kegiatan yng berkenaan dengan metode pengumpulan data pustaka, membaca, mencatat serta mengolah bahan penelitian".Dalam metode ini penulis mengumpulkan data dari berbagai sumber yang telah ada yang sesuai dengan topik pembahasan dan objek yang diteliti.

\section{Analisis Data}

Dalam penganalisaan data yang telah diperoleh, maka penulis menggunakan metode kualitatif dan deskriptif dengan melakukan pengamatan data dimulai dengan memahami dan mempelajari seluruh data yang tersedia.

\section{Metode Kualitatif}

Data kualitatif bersifat tidak terstruktur, sehingga variasi data dari sumbernya mungkin sangat beragam. Penyebabnya adalah para partisipan yang terlibat dalam riset diberi kebebasan dalam mengutarakan pendapat. Kebebasan partisipan dalam menyampaikan pendapat membuat periset mampu memperoleh pemahaman yang lebih baik terhadap masalah yang sedang diteliti. Dengan demikian, data kualitatif cenderung sesuai digunakan dalam riset eksploratori. Melakukan observasi dengan percobaan terhadap sistem akuntansi dengan menggunakan software Acosys sesuai dengan prosedur-prosedur implementasinya. Berikut tahapan-tahapan observasi :

- Pembuatan daftar akun, sesuai dengan kebutuhan perusahaan

- Input jurnal transaksi

- Input transaksi fitur-fitur sesuai kebutuhan akuntansi

\section{Metode Deskriptif}

Menampilkan laporan yang diinginkan

Menurut (Heinzh, 2008) penelitian yang berdasarkan pengalaman, apakah pengalaman sendiri ataupun orang lain. Penelitian deskripstif juga merupakan penelitian dimana pengumpulan data untuk mengetes pertanyaan penelitian atau hipotesis yang berkaitan dengan keadaan dan kejadian sekarang. Mereka melaporkan keadaan objek atau subjek yang diteliti sesuai dengan apa adanya. Pada umumnya tujuan utama penelitian deskriptif untuk menggambarkan secara sistematis fakta dan karakteristik objek dan subjek yang diteliti secara tepat.

\author{
HASIL DAN PEMBAHASAN \\ Hasil \\ Implementasi Microsoft Excel
}




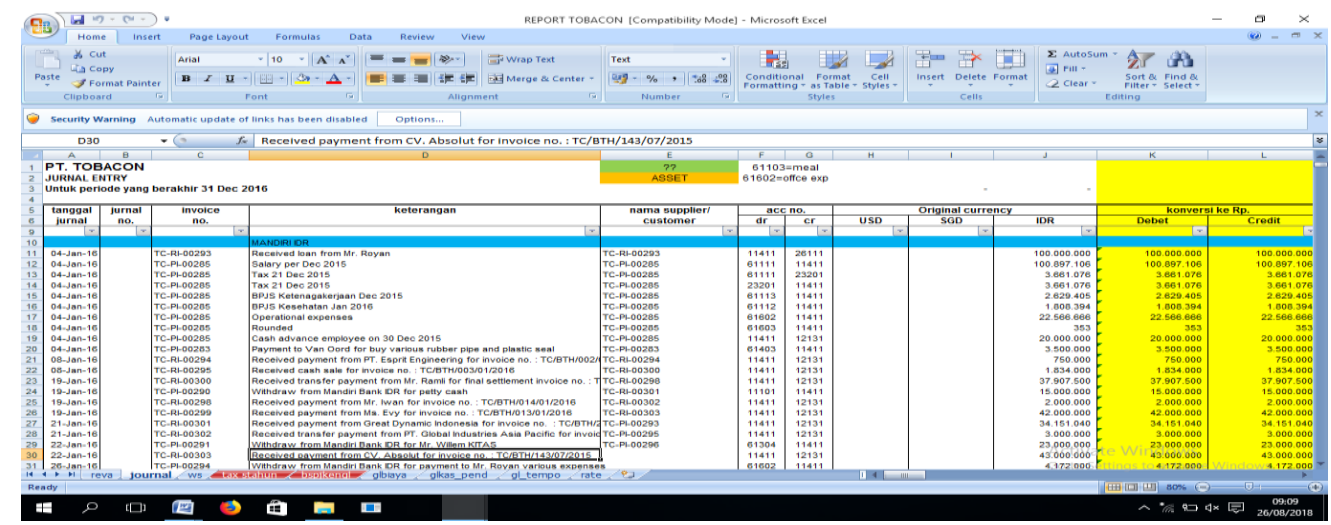

Gambar 1. Jurnal Umum

Dari tampilan diatas terlihat cara dalam mencata jurnal umum pada Microsoft Excel. Pada bagian ini mungkin agak terlihat rumit akan tetapi dalam implementasinya hampir sama dengan Acosys.

\section{Implementasi Software Acosys}

Aktivasi sesuai kebutuhan perusahaan, yang sering digunakan untuk penggunaan standar yaitu A,B,C,D:

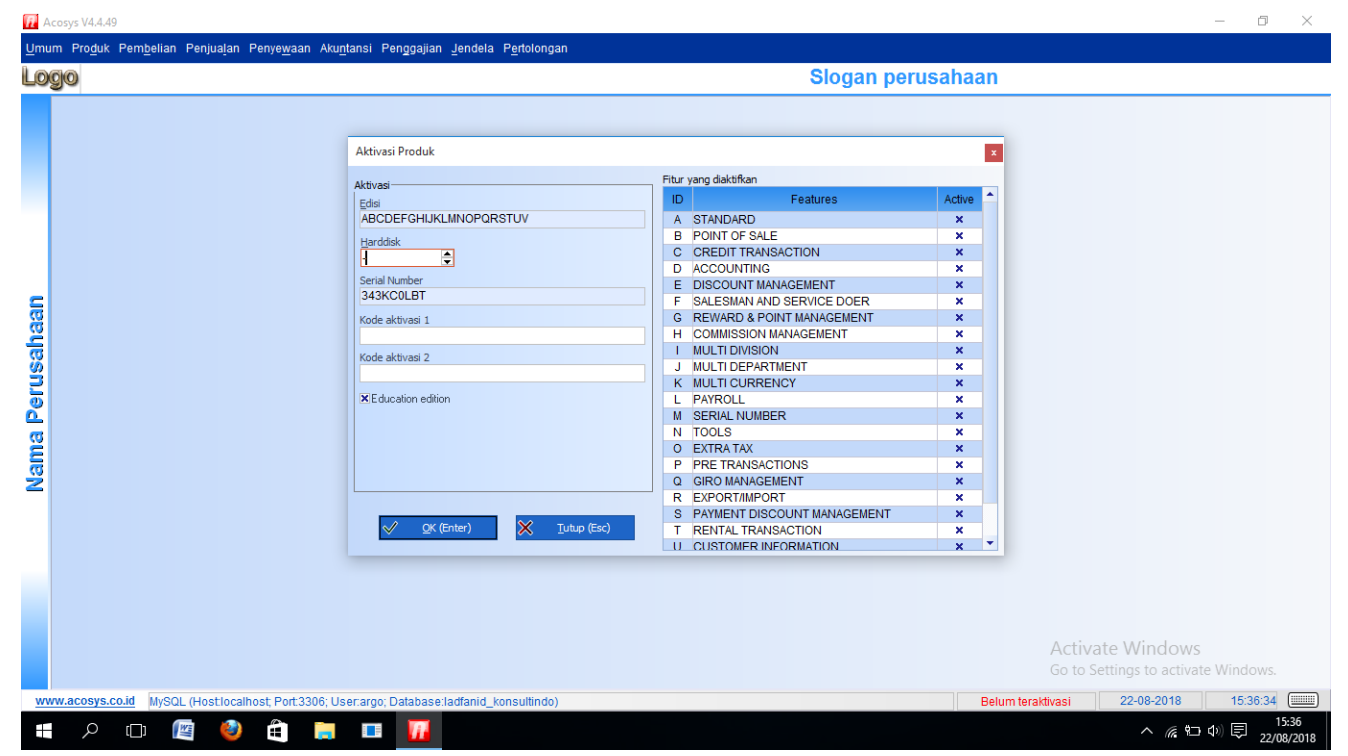

Gambar 2. Fitur Pada Acosys

Fitur Standar adalah fitur dasar yang memadai untuk kebutuhan dasar dalam bisnis. Fitur ini telah mencakup transaksi pembelian, penjualan, persediaan, hutang dan laporanlaporan.Fitur Standard sebagai fitur dasar dapat digabungkan dengan fitur lain, misalnya untuk bisnis retail yang stand alone (berdiri sendiri) dapat digabung dengan fitur POS.

Sedangkan perusahaan yang kompleks bisa menggabungkan fitur Standard dengan fitur Credit Transaction, Accounting, Discount Management, Salesman and Servicedoer, Reward and Point Management, Commision Management, Multi Division, Multi Department, Multy Currency, Payroll, Serial Number and Expired Date, Tools, Extra Tax, Pre Transaction, Giro Management, Export/Import, Payment Discount Management, Rental Transaction, Product Information dan Acosys Analysis Center.Fitur Small Business dan Education Edition tidak dapat digabungkan dengan fitur Standard, karena kedua fitur tersebut adalah fitur mandiri yang bisa berdiri sendiri tanpa fitur lain.

Pembahasan

Pembahasan dalam penelitian ini adalah sebagai berikut : 
1. Sistem akuntansi menggunakan Microsoft Excel yang diterapkan dalam penyajian laporan keuangan PT Ladfanid Konsultindo Batam.

Dalam menggunakan Microsoft Excel dalam penyajian laporan keuangan, pengguna harus membangun sistem terlebih dahulu. Maksud membangun sistem disini adalah membuat rumus-rumus serta link-link akunnya supaya bisa terintegrasi setiap entri data dan laporan yang diinginkan sesuai kebutuhan laporan keuangan. Setelah semua diatur, baru bisa mulai melakukan input daftar akun atau chart of account sesuai dengan kebutuhan transaksi. Didalam Microsoft Excel nama-nama akun diinput secara manual. Akan tetapi dalam pelaksanaannya, pada Microsoft Excel dalam penyajian laporan keuangan terutama untuk perusahaan dagang dan manufaktur dalam perhitungan harga pokok penjualan harus ada pengkalasifikasian terlebih dahulu karena dalam Microsoft Excel tidak memiliki menu khusus dalam penyajian pembelian dan penjualan sehingga ada beberapa pengklasifikasian dalam pada sheet yang berbeda. Setiap sheet yang harus saling terintegrasi untuk menghasilkan laporan secara otomatis. Karena banyak rumus-rumus dan bahasa pemrograman pada Microsoft Excel ini dalam penyusunan laporan keuangan sehingga aplikasinya agak berat yang terkadang menggangu user dalam bekerja.

2. Sistem akuntansi yang digunakan perusahaan sudah memadai dan dapat diandalkan.

Sistem akuntansi yang digunakan saat ini yaitu Acosys, yang merupakan sistem akuntansi yang lebih memadai dan dapat diandalkan dari pada dengan menggunakan Microsoft Excel. Acosys dapat dikategorikan sistem yang kompleks dalam penyusunan laporan keuangan karena memiliki fitur-fitur yang dapat digunakan sesuai dengan kebutuhan perusahaan. Mulai dari fitur umum, produk yang dijual, fitur pembelian, fitur penjualan, fitur penyewaan, fitur akuntansi, dan pengajian. Ketika transaksi telah diinput maka user bisa menampilkan laporan sesuai yang diinginkan karena Acosys telah menyediakan laporan keuangan secara lengkap sesuai data yang diinginkan.

3. Faktor-faktor yang mempengaruhi kesuksesan setelah implementasi sistem informasi akuntansi berbasis software Acosys pada PT Ladfanid Konsultindo Batam.

Yang membuat implementasi sistem informasi akuntansi berbasis software Acosys dapat bemanfaat bagi PT Ladfanid Konsultindo Batam karena memiliki fitur-fitur yang lengkap yang dapat memudahkan user dibandingkan dengan Microsoft Excel yang sudah digunakan sebelumnya oleh perusahaan. Laporan keuangan yang dihasilkan dapat berupa berbagai format baik dalam bentuk Microsoft Excel maupun dalam bentuk PDF. Serta setiap transaksi yang sudah diinput secara otomatis segala macam bentuk laporan yang berkaitan dengan keuangan dapat diakses dengan cepat sesuai kebutuhan. Mungkin hal ini merupakan hal yang umum bagi setiap software akuntansi, yang jarang dimiliki oleh software lain akan tetapi dimiliki oleh Acosys yaitu software Acosys dapat digunakan selamanya tanpa harus ada biaya tambahan untuk meng- update seperti yang lain.

\section{SIMPULAN}

Dari hasil analisis data yang dilakukan, maka dapat disimpulkan sebagai berikut :

1. Karena dalam Microsoft Excel tidak memiliki menu khusus atau fitur yang dapat digunakan dalam penyajian laporan keuangan sehingga banyak proses yang harus dikerjakan secara manual sehingga dapat memiliki kelemahan dibanding dengan menggunakan software akuntansi.

2. Sistem akuntansi yang digunakan saat ini yaitu Acosys, yang merupakan sistem akuntansi yang lebih memadai dan dapat diandalkan dari pada dengan menggunakan Microsoft Excel. Acosys dapat dikategorikan sistem yang kompleks dalam penyusunan laporan keuangan karena memiliki fitur-fitur yang dapat digunakan sesuai dengan kebutuhan perusahaan.

3. Yang membuat implementasi sistem informasi akuntansi berbasis software Acosys dapat bemanfaat bagi PT Ladfanid Konsultindo Batam karena memiliki fitur-fitur yang lengkap 

yang dapat memudahkan user serta dapat digunakan selamanya tanpa harus ada biaya tambahan untuk memperbarui.

\section{SARAN}

Dari penelitian yang telah penulis lakukan, maka penulis memberikan saran :

1. Diharapkan PT Ladfanid Konsultindo Batam dapat memaksimalkan penataan laporan keuangan denga didukung dengan sofware yang memadai.

2. Sebaiknya perusahaan lebih banyak menari referensi sofware akuntansi yang lain agar dapat menjadi perbandingkan untuk mencari yag terbaik .

3. Pada peneliti selanjutnya untuk dapat mengembangkan pembahasan penelitian dengan mengembangkan variabel maupun objek penelitian.

\section{DAFTAR PUSTAKA}

Ardana, C. dan L. H. (2016). Sistem Informasi Akuntansi. Mitra Wacana Media.

Bodnar, G. H. and W. S. H. (2010). Accounting Information System. Pearson Education Inc.

Heinzh, F. (2008). Pedoman Karya Ilmiah. Kanisus.

Mestika, Z. (2008). Metode Penelitian Kepustakaan. Yayasan Obor Indonesia.

Widjajanto, N. (2010). Sistem Informasi Akuntansi. Erlangga. 